This is a pre-print of an article published in the Journal of Engineering and Technology Management. The final authenticated version is available online at:

Berbegal-Mirabent, J. (2018). The influence of regulatory frameworks on research and knowledge transfer outputs: An efficiency analysis of Spanish public universities. Journal of Engineering and Technology Management, 47: 68-80.

https://doi.org/10.1016/j.jengtecman.2018.01.003

\title{
The influence of regulatory frameworks on research and knowledge transfer outputs: An efficiency analysis of Spanish universities
}

\begin{abstract}
Quality assurance criteria and guidelines for the European Higher Education Area cover the assessment of academic staff, revealing the importance of the activities conducted by faculty members. In 2007 Spain reformed its regulatory framework to give priority to research and knowledge transfer activities. It is in this context that we examine the efficiency of Spanish public universities and their evolution during the period 20062010. First, we use data envelopment analysis to calculate the efficiency scores of each year. Next, using the Malmquist index we evaluate efficiency changes. Lastly, using truncated regression analysis we determine the external factors influencing universities' efficiency.
\end{abstract}

Keywords: universities, research and knowledge transfer, data envelopment analysis, Malmquist index, truncated regression.

JEL Classification: C67, I21, I23. 


\section{The influence of regulatory frameworks on research and knowledge transfer outputs: An efficiency analysis of Spanish universities}

\section{Introduction}

The enhanced institutional autonomy that universities have been given has been accompanied by requirements for greater accountability and more stringent, detailed quality assurance procedures. There is an abundance of public accountancy reports on universities' performance. Traditionally, these reports depended heavily on data from governmental statistical agencies that were far from being collected on an annual, standardized and systematic basis (Salerno 2004). Moreover, the available data tended to be aggregated (rather than reported on a per institution or per academic discipline basis), country-specific and to largely ignore knowledge transfer activities.

This changed with the rise of the evaluative state, the improvement in information systems and the emergence of business analytics; it is now easy to access large amounts of valuable information. The body of data from the higher education system contains a very large number of indicators, metrics and complex associations. Internal use of this information could help university managers to allocate resources better and improve performance.

Increasingly institutes, research centers, public and independent organizations and companies operating in the media sector are reporting more and more information about universities' performance online. Making it easier to access such information has several implications. It enables universities to benchmark their performance and decide their strategy without resorting to complex market studies, because the information they require is now at their fingertips. It also makes it easier to improve current proxies for universities' inputs and outputs. A further benefit is that there is the potential to aggregate and analyze the raw data to help students, potential partners and governments make better decisions (Soares 2012).

In this study we exploited this newly available information. On the basis of comprehensive data reported by various online sites we developed a model to assess how efficient are Spanish public universities in conducting research and knowledge transfer activities. 
There are several procedures for assessing university performance; we chose to use Data Envelopment Analysis (DEA), a non-parametric efficiency technique. There are several advantages to this method. DEA models are very flexible and do not require the specification of any particular functional form for the best practice frontier (Seiford, Thrall 1990). This approach is particularly attractive for modelling organizations -such as universities- with multiple inputs and/or outputs, and in the absence of market prices.

In the higher education field DEA models tend to be used to evaluate the overall performance of universities or their teaching activities (see Berbegal-Mirabent, Solé 2012 for an extensive review). In this study, however, we focused on research and knowledge transfer (RKT) outputs. There were three reasons for this. First, as knowledge creators, universities are responsible for a high percentage of the research which takes place in the developed world. Second, research is crucial to universities' continuing existence. RKT activities help universities to provide a stimulating learning environment, attract and retain qualified faculty and students, ensure that curricula cover topics at the cutting edge and contribute to the economic development of their region (Hazelkorn 2005). We therefore argue that more attention should be paid to how universities allocate resources in pursuit of RKT outputs. Third, RKT outcomes are increasingly considered in evaluation procedures and are regarded as among the best indicators of success (Shattock 2009).

Our empirical work considers the Spanish public higher education system during the period 2006-2010. In Spain it is compulsory to assess the teaching and research credentials of candidates when hiring staff. The National Agency for Quality Assessment and Accreditation (ANECA) is the body responsible for all such evaluations. In 2007 several modifications to the framework regulating the hiring and contracting of academic staff were introduced. For the most part the changes mirrored the shift in universities' activities, from a teaching-oriented model to a research-oriented one. This meant that the research credentials of candidates for university posts became more important relative to the other components of an academic CV (i.e. educational background, teaching experience, work experience).

The aim of this study is to assess how the incorporation of more stringent research requirements into the regulatory framework has influenced universities' RKT activities, and more precisely, whether the efficiency of universities improved or worsened as a consequence of the modifications. To this end, we carried out a threestage analysis (i) an efficiency analysis (using data from 2006, 2008 and 2010), (ii) 
investigation of changes in efficiency using the Malmquist index and (iii) development of a truncated regression model to determine the external factors influencing efficiency.

The remainder of this paper is organized as follows. The next section discusses basic and applied research outcomes, the indicators commonly used to proxy these activities and the incentives for researchers to carry out both types of research. After this we outline the Spanish regulatory framework. This is followed by a description of the method and presentation of the data. Results are then reported in the following section. The paper ends with a discussion of policy implications and some concluding remarks.

\section{Basic vs. applied research outcomes}

Research is an intrinsically competitive endeavor encompassing basic academic investigations and collaborative partnerships between universities and industry. Outputs are traditionally measured in terms of bibliometric data (Sarrico et al. 2010). Such data are freely available and facilitate the use of measures related to the number of papers published in scientific journals or citation counts. Although it has been argued that these metrics reflect both the quantity and quality of research activity (Abramo et al. 2008), they are usually criticized for being vague and incomplete, and failing to capture the full range of universities' research productivity (Van Raan 2005). Some critics (e.g. Coccia 2008) have claimed that publications other than journals -conference proceedings, books, book chapters and reports- are usually undervalued in evaluations, although they reach a wider audience and disseminate research beyond academia. It is nevertheless widely accepted that such publications are usually of lower quality than articles in peerreviewed journals.

Variables linked to indices and bibliometric data are, however, widely used in assessment procedures and ranking systems. For instance, in the Academic Ranking of World Universities (ARWU) 20\% of the total score depends on the number of papers published in journals indexed in the Science Citation Index (SCI) and the Social Science Citation Index (SSCI). Another $20 \%$ is based on the number of papers published in the journals Nature and Science; and $20 \%$ is based on the number of citations per researcher, a proxy for impact. In summary, $60 \%$ of the total ARWU score is based on subjective metrics that, although they are based on agreed quality standards and are accepted by the academic community, present an incomplete picture of an institution's 
research performance. Similar methods are used by universities and external agencies to assess the performance of individual academics for recruitment and promotion purposes. This means that in order to remain in academia scholars are forced to concentrate on producing the outputs regarded as most valuable in these assessment frameworks. It is essential to publish high quality articles in top journals, particularly for young academics and staff who do not have a permanent position.

Nevertheless, if research activities are to be meaningful they must produce economically useful knowledge with industrial relevance (Hsu et al. 2016, BerbegalMirabent et al. 2015). This assumes that the market is a driver of external collaborations between academia and industry, and that this improves universities' performance and facilitates access to additional, non-public funding and resources. In other words, if the knowledge generated by universities is not disseminated it loses its value.

For the dissemination of knowledge to takes place, universities and businesses must identify common interests in order to build alliances that enable the exploitation of universities' scientific knowledge and make an efficient use of their infrastructures and advanced services (Plewa et al. 2013). Patenting, licensing agreements and collaborative research projects are the traditional channels through which research results are transferred to industry (van der Ploeg, Veugelers 2008), but there is another way to exploit or transfer knowledge generated in the university sector. Scientific knowledge can be the starting point for a business idea, and by extension, the birth of new a company. Spin-offs represent the entrepreneurial route to commercialization of public research (Rasmussen 2008).

Although the benefits of knowledge transfer activities are widely documented in the literature (Geuna, Muscio 2009) they are still undervalued relative to traditional basic research outcomes (i.e. publications). Boardman and Bozeman (2007) and Boardman and Ponomariov (2007) provided empirical evidence that academics in pretenure positions are reluctant to engage in knowledge transfer activities, preferring to devote their time to basic research activities. Similarly, Balsmeier and Pellens (2014) and Agarwal and Ohyama (2013) found that although the number of publications was positively associated with promotion prospects, researchers with a track record of patenting activity were more likely to drop out of academia. These findings suggests that from the researcher's perspective the main motivation for engaging in knowledge transfer activities is because they potentially offer access to new sources of funding for research or activities one would not otherwise be able to undertake (mainly due to the 
lack of resources); knowledge transfer activities may also generate new ideas which can be developed further.

\section{Spanish regulatory framework}

\subsection{Career path}

Over the past 15 years there have been substantial changes to the procedures for recruiting and employing academics in the Spanish higher education system. In 2001 a new legal framework, the LOU, was approved to replace the Organic Law of University Reform (LRU) 11/1983. The types of contract available in the academic sector differentiate between civil servants (permanent faculty) and non-civil servants (fixedterm faculty).

The requirements for becoming a civil servant were specified by Royal Decree $774 / 2002$. The procedure was similar to that of oppositions, where candidates were required to pass a series of examinations and to demonstrate their teaching ability and expertise in a particular area of knowledge. The Reform of the Organic Law of Universities (RLOU) 4/2007 came into force in April 2007. This eliminated some contractual figures, and replaced the examination process with an accreditation system specifying the criteria that all candidates were required to meet before being hired by a university in a particular capacity. The accreditation system was effective from 2008, and should be administered by an external agency (ANECA or the competent regional quality assurance agency). The new procedure was expected to make the recruitment process more competitive and enable universities to choose the candidates that best suited their requirements.

The LOU (2001) also provided for important changes in the assessment and recruitment of non-civil servants. The aim was to consolidate the body of skilled researchers. The number of roles available expanded, in increasing order of status they were: assistant, $\mathrm{PhD}$ assistant lecturer, collaborating lecturer and $\mathrm{PhD}$ lecturer. $\mathrm{A}$ positive external assessment was also a prerequisite for appointment to any of these roles, with the exception of assistant, for which universities were free to set their own criteria. Under the terms of Royal Decree 1052/2002 assessments were carried out by the ANECA or the competent regional authority on the basis of a CV. Some modifications to the assessment procedure were introduced by the RLOU 4/2007, most 
notably the criteria for the level of research performance required to access the various academic positions were made more stringent.

The LOU (2001) also recognized a third category of academic staff, namely part-time faculty, i.e. specialists with recognized competence and a record of current professional activity outside the university who performed a reduced amount of university teaching, were paid hourly and were not required to carry out any research activities. Because they were not required to carry out research we do not consider them in this paper.

\subsection{Accreditation system}

There is an accreditation system for both civil servant and non-civil servant academics. The primary objective of the evaluation is to ensure that candidates for academic positions have an appropriate level of academic merit. ANECA implements two assessment programs: the Assessment Program for civil servant faculty (ACADEMIA) and the Academic Staff Evaluation Program (PEP) for non-civil servant faculty. The weight assigned to the various components of a $\mathrm{CV}$ (i.e. teaching experience, research experience, educational background, and work experience) varies according to the teaching body, academic discipline and academic position.

At this point it is worth mentioning that the different categories are substantially research-biased. The higher the position, the more important are one's research credentials (i.e. publication history, research projects, knowledge transfer). Table 1 compares the indicators and weights of the various components for all the academic positions to which the system applies $(\mathrm{PhD}$ assistant lecturer, $\mathrm{PhD}$ lecturer, senior lecturer and full professor) based on the modifications introduced by the Reform of the Organic Law of Universities 4/2007. Table 1 makes it clear that research experience typically accounts for at least half of the total score, thus confirming that research outputs are more highly valued than the other criteria. 
Table 1. Criteria and weights assigned to each indicator and academic post, according to ANECA.

\begin{tabular}{|c|c|c|c|c|c|c|c|c|c|}
\hline \multirow[b]{2}{*}{ Criteria } & \multirow[b]{2}{*}{ Indicator } & \multicolumn{4}{|c|}{ PEP } & \multicolumn{4}{|c|}{ ACADEMIA } \\
\hline & & \multicolumn{2}{|c|}{$\begin{array}{c}\text { PhD assistant } \\
\text { lecturer }\end{array}$} & \multicolumn{2}{|c|}{$\mathrm{PhD}$ lecturers } & \multicolumn{2}{|c|}{$\begin{array}{l}\text { Senior } \\
\text { lecturer }\end{array}$} & \multicolumn{2}{|c|}{$\begin{array}{c}\text { Full } \\
\text { professor }\end{array}$} \\
\hline \multirow{5}{*}{$\begin{array}{l}\text { Educational } \\
\text { background }\end{array}$} & $\mathrm{PhD}$ & \multirow{4}{*}{\multicolumn{2}{|c|}{21}} & \multirow{4}{*}{\multicolumn{2}{|c|}{6}} & \multirow{5}{*}{\multicolumn{2}{|c|}{5}} & \multirow{5}{*}{\multicolumn{2}{|c|}{ - }} \\
\hline & Scholarships and grants & & & & & & & & \\
\hline & Academic background & & & & & & & & \\
\hline & Mobility & & & & & & & & \\
\hline & Research posts (coordination) & \multicolumn{2}{|l|}{-} & \multicolumn{2}{|l|}{-} & & & & \\
\hline \multirow{6}{*}{$\begin{array}{l}\text { Teaching } \\
\text { experience }\end{array}$} & Teaching experience & \multirow{3}{*}{\multicolumn{2}{|c|}{9}} & \multirow{3}{*}{\multicolumn{2}{|c|}{30}} & \multirow{6}{*}{\multicolumn{2}{|c|}{37}} & \multirow{6}{*}{\multicolumn{2}{|c|}{32}} \\
\hline & Teaching training & & & & & & & & \\
\hline & $\begin{array}{l}\text { Teaching innovation and teaching } \\
\text { material }\end{array}$ & & & & & & & & \\
\hline & Mobility & \multirow{3}{*}{\multicolumn{2}{|c|}{-}} & \multirow{3}{*}{\multicolumn{2}{|c|}{-}} & & & & \\
\hline & Academic posts (coordination) & & & & & & & & \\
\hline & Academic supervision (thesis) & & & & & & & & \\
\hline \multirow{7}{*}{$\begin{array}{l}\text { Research } \\
\text { experience }\end{array}$} & $\begin{array}{l}\text { Research projects and research } \\
\text { contracts }\end{array}$ & $5-9$ & \multirow{7}{*}{60} & $5-12$ & \multirow{7}{*}{60} & $4-7$ & \multirow{7}{*}{50} & $6-10$ & \multirow{7}{*}{55} \\
\hline & Technology transfer & \multirow{2}{*}{$26-35$} & & \multirow{2}{*}{$26-35$} & & $2-9$ & & $3-12$ & \\
\hline & Publications (articles) & & & & & \multirow{2}{*}{$27-37$} & & \multirow{2}{*}{$27-37$} & \\
\hline & Books and book chapters & $3-16$ & & $3-16$ & & & & & \\
\hline & Conferences and seminars taught & 9 & & $2-5$ & & $3-5$ & & $3-5$ & \\
\hline & Academic supervision (thesis) & - & & 4 & & & & & \\
\hline & Other research merits & 4 & & $1-2$ & & & & & \\
\hline $\begin{array}{l}\text { Work } \\
\text { experience }\end{array}$ & $\begin{array}{l}\text { Work experience outside the } \\
\text { university }\end{array}$ & 5 & & 2 & & 3 & & 3 & \\
\hline Other merits & Other merits & 5 & & 2 & & 2 & & 2 & \\
\hline Coordination & Academic posts & - & & - & & 5 & & 10 & \\
\hline Total & & 100 & & $\begin{array}{r}100 \\
(+2 \mathrm{ext}\end{array}$ & & $\begin{array}{r}100 \\
(+2 \mathrm{ex}\end{array}$ & & $\begin{array}{r}100 \\
(+2 \mathrm{ex}\end{array}$ & \\
\hline Minimum req & ired score for a positive evaluation & 55 & & 55 & & 65 & & 80 & \\
\hline
\end{tabular}

Note: For those criteria that scores vary depending on the discipline, we present the range values.

\section{Data and method}

\subsection{Data}

Our main source of information was the Observatory of Spanish University Research Activity (IUNE) online database, which compiles information from various official sources and makes it publicly available. We also used the biannual reports of the Council of Rectors of Spanish Universities (CRUE) and the annual reports of the Spanish Network of Technology Transfer Offices (RedOTRI). Additional information about regional variables was obtained from the Spanish National Institute of Statistics (INE) website.

The original database consisted of information on 47 Spanish public universities for the academic years 2006, 2008 and 2010. Although we were able to obtain data for 
the majority of fields there were inevitably some missing values; in consequence we excluded three universities from analysis, leaving a final sample of 44 universities.

Statistical analysis was carried out using STATA (version 13). Efficiency scores and Malmquist index values were calculated using the OnFront software (version 2.0).

\subsection{Efficiency analysis: DEA}

Efficiency analysis usually uses frontier methods grounded in economic production theory to deal with multiple inputs yielding multiple outputs. Farrell (1957) stated that technical efficiency could be analyzed in terms of observed deviations from an ideal frontier isoquant, thus characterizing the relationship between observed production and a potential production level in terms of the observations. This definition of efficiency relates to the use of resources, that is, how efficiently inputs are transformed into outputs in comparison with a maximally efficient unit. A production unit can be considered technically efficient if it is impossible to produce more of any output without producing less of some other output or consuming more inputs (Koopmans 1951).

Farrell's efficiency measure was popularized by Charnes et al. (1978) who introduced a technique, DEA, for assessing the efficiency of a sample of organizations (decision making units; DMUs). DEA-based measures are non-parametric, deterministic techniques that use linear programming mathematical models to approximate the true but unknown technology; they do not impose restrictions on sample distribution, nor do they require input and output prices. The best practice frontier is determined by the performance of the most efficient DMUs and DEA computes an inefficiency score for other DMUs which reflects their distance from this frontier.

DEA models are based on several assumptions. First, one must define the frontier production function assuming constant returns to scale (CRS) or variable returns to scale (VRS). For this study we used VRS, which allows one to estimate distances to the production frontier whilst controlling for the size of the benchmarks (Cooper et al. 2007). Although the assumption of CRS is attractive, the extant evidence indicates that in practice VRS are much more common (Chambers, Pope 1996). The second assumption deals with the choice of measurement orientation (input minimization or output maximization). Since our analysis focuses on public universities we opted to use an output orientation on the grounds that in public universities the 
workforce and budget tend to be fixed and managers are asked to maximize output from the available resources (Tone, Sahoo 2003).

Given these considerations, the linear equation that must be solved is presented in Equation (1). Maximization of $\delta^{i}$ involves the production of the highest level of outputs $(y)$ possible given the resources available $(x)$. The term $\delta^{i}$ represents the efficiency score for each unit (university); for efficient universities, i.e. those situated on the best practice frontier, $\delta^{\mathrm{i}}=1$. Values of $\delta^{\mathrm{i}}>1$ indicate the degree of inefficiency as a function of distance from the best practice frontier.

$$
\begin{aligned}
& T\left(x^{i^{\prime}}, y^{i^{\prime}}\right)=\max \delta^{i} \\
& \text { subject to } \sum_{i=1}^{N} \lambda^{i} y_{m}^{i} \geq \delta^{i} y_{m}^{i^{\prime}} \quad, m=1, \ldots, M \\
& \sum_{i=1}^{N} \lambda^{i} x_{j}^{i} \leq x_{j}^{i^{\prime}} \quad, j=1, \ldots, J \\
& \sum_{i=1}^{N} \lambda^{i}=1 \\
& \lambda^{i} \geq 0 \quad, i=1, \ldots, N
\end{aligned}
$$

Our model assumes that universities use three inputs $(x)$ to produce four RKT outputs (y). Descriptive statistics are presented in Table 2.

Concerning the outputs, we consider those indicators that are most valued by the ANECA to accredit professors. As shown above in Table 1, these outputs are: publications, technology transfer outputs and research projects. Although the weights assigned to the different outputs vary according to the academic position and discipline we can conclude that these outputs are relevant indicators as they are the main determinants of whether a candidate is evaluated positively.

The publications variable was operationalized as number of academic papers published in the ISI Web of Knowledge. The reasoning for this was threefold. First, the ANECA guidelines state that publications in journals included in this database are more valuable than those in journals included in other databases. Second, the ISI Web of Knowledge is considered to reflect both quantity and quality (Kao, Hung 2008). Acceptance of papers is based on a blind peer review process which follows quality standards accepted by the academic community. Third, information on the number of papers published is reliable and well documented.

Technology transfer outputs were operationalized via two indicators: number of patents awarded by the Spanish Office of Patents and Trade Marks (OEPM) and number of spin-off companies created. Although the granting of a patent does not guarantee the future marketability of a technology it indicates that the university has the capacity for 
technological innovations (Anderson et al. 2007). Spin-off companies represent the entrepreneurial route to commercialization of public research (Rasmussen 2008) and are one of the most appropriate indicators of knowledge transfer activities.

Lastly, we took into account the number of research projects granted by the Spanish Ministry of Education. Because research projects are awarded on a competitive basis this indicator captures a university's ability to conduct high quality, innovative research activities. This criterion is particularly relevant in the fields of engineering, and the medical and experimental sciences.

Table 2. Descriptive statistics for the selected variables.

\begin{tabular}{|c|c|c|c|c|c|c|c|c|}
\hline \multirow[b]{2}{*}{ Year } & \multirow[b]{2}{*}{ Statistic } & \multicolumn{3}{|c|}{ Inputs } & \multicolumn{4}{|c|}{ Outputs } \\
\hline & & Faculty & TTO staff & $\begin{array}{c}\mathrm{R} \& \mathrm{D} \\
\text { expenditure }^{*}\end{array}$ & Publications & Patents & Spin-offs & $\begin{array}{l}\text { Research } \\
\text { projects }\end{array}$ \\
\hline \multirow{4}{*}{2006} & Mean & 1140.523 & 14.685 & 55.286 & 714.023 & 6.159 & 3.318 & 57.386 \\
\hline & Std. Dev. & 810.938 & 11.299 & 42.577 & 592.220 & 6.412 & 4.659 & 42.129 \\
\hline & Min. & 145.000 & 3.500 & 8.852 & 99.000 & 0.000 & 0.000 & 11.000 \\
\hline & Max. & $3,850.000$ & 45.000 & 195.800 & $2,698.000$ & 27.000 & 22.000 & 192.000 \\
\hline \multirow{4}{*}{2008} & Mean & $1,184.159$ & 15.439 & 68.936 & 858.705 & 5.636 & 2.409 & 54.159 \\
\hline & Std. Dev. & 828.722 & 13.111 & 51.992 & 714.888 & 6.024 & 3.068 & 39.699 \\
\hline & Min. & 250.000 & 3.000 & 8.360 & 107.000 & 0.000 & 0.000 & 8.000 \\
\hline & Max. & $3,995.000$ & 66.000 & 205.157 & $3,211.000$ & 25.000 & 12.000 & 187.000 \\
\hline \multirow{4}{*}{2010} & Mean & $1,211.682$ & 14.515 & 74.282 & 991.114 & 9.318 & 2.568 & 54.477 \\
\hline & Std. Dev. & 822.439 & 12.087 & 52.894 & 795.420 & 8.936 & 3.351 & 37.251 \\
\hline & Min. & 274.000 & 4.000 & 17.109 & 148.000 & 1.000 & 0.000 & 8.000 \\
\hline & Max. & $3,931.000$ & 56.000 & 199.740 & $3,548.000$ & 43.000 & 13.000 & 158.000 \\
\hline \multirow{4}{*}{ Total } & Mean & $1,178.788$ & 14.880 & 66.168 & 854.614 & 7.038 & 2.765 & 55.341 \\
\hline & Std. Dev. & 814.974 & 12.101 & 49.650 & 709.548 & 7.368 & 3.750 & 39.465 \\
\hline & Min. & 145.000 & 3.000 & 8.360 & 99.000 & 0.000 & 0.000 & 8.000 \\
\hline & Max. & $3,995.000$ & 66.000 & 205.157 & $3,548.000$ & 43.000 & 22.000 & 192.000 \\
\hline
\end{tabular}

Note: Sample size: 44 universities (132 observations including years 2006, 2008 and 2010).

${ }^{*} \mathrm{R} \& D$ expenditure in million euros. Data for years 2006 and 2008 were inflation-corrected and reported in $2010 €$.

As for the selected inputs, the first input we considered was human resources. Universities are labor-intensive organizations, and as such the labor force is a critical input. We therefore included the number of faculty members responsible of carrying out RKT activities. The efficient running of a university also depends on the technical and administrative workers who manage its day-to-day operations and support RKT activities. In this analysis we represented this input as the number of technical staff working in a university's Technology Transfer Office (TTO). Applying for a patent, submitting a project proposal or starting a new business all demand specific skills that researchers might not possess, but are tasks that can be more easily performed with the support of TTO staff. Finally, the third input we considered was expenditure on research and development (R\&D) activities. As shown in Table 2, Spanish public universities 
have increased their $\mathrm{R} \& \mathrm{D}$ expenditure, indicating the increase in importance accorded to this area of activity.

\subsection{Changes in efficiency: Malmquist index}

We investigated changes in efficiency for the periods 2006-2008 and 2008-2010 using the non-parametric Malmquist index (see Färe et al. 1994, 1992 for pioneering research on the Malmquist index). This approach has been applied to a number of services, including the higher education system (e.g. Kim 2013, Agasisti, Pohl 2012, Groot, García-Valderrama 2006).

The Malmquist index compares data from two different periods, $t$ and $t+1$, to the same reference technology from period $t$. Consistent with the initial assumption (outputoriented), the output-based Malmquist index of change in productivity is specified by the equation formulated by Coelli et al. (1998) and reproduced in Equation (2):

$$
M_{0}^{t+1}\left(y_{t}, x_{t}, y_{t+1}, x_{t+1}\right)=\left[\frac{D_{0}^{t}\left(y_{t+1}, x_{t+1}\right)}{D_{0}^{t}\left(y_{t}, x_{t}\right)} \times \frac{D_{0}^{t+1}\left(y_{t+1}, x_{t+1}\right)}{D_{0}^{t+1}\left(y_{t}, x_{t}\right)}\right]^{1 / 2},
$$

where the subscript $O$ indicates an output orientation, $M$ is the productivity at the most recent production point $(x t+1, y t+1)$ (using period $t+1$ technology) expressed relative to the earlier production point $(x t, y t)$ (using period $t$ technology) and $D$ is an output distance function. The Malmquist index can also be expressed in the form given as Equation (3):

$$
M_{0}^{t+1}\left(y_{t}, x_{t}, y_{t+1}, x_{t+1}\right)=\frac{D_{0}^{t+1}\left(y_{t+1}, x_{t+1}\right)}{D_{0}^{t}\left(y_{t}, x_{t}\right)} \times\left[\frac{D_{0}^{t}\left(y_{t+1}, x_{t+1}\right)}{D_{0}^{t+1}\left(y_{t+1}, x_{t+1}\right)} \times \frac{D_{0}^{t}\left(y_{t}, x_{t}\right)}{D_{0}^{t+1}\left(y_{t}, x_{t}\right)}\right]^{1 / 2},
$$

The first part of Equation (3) is a measure of efficiency change, i.e. the technical efficiency in period $t+1$ relative to the technical efficiency in period $t$ ("pure" efficiency change, indicating the ability of universities to improve their own performance with respect to the performance of the others). The second part measures movement relative to the production frontier, reflecting the technical change. Values $>1$ indicate an increase, values $<1$ denote a decrease and a value of 1 represents no change. The Malmquist index resulting from combining the two components is equal to one if there are no changes in technical efficiency and frontier changes. When there is a net positive or negative change in efficiency the index is respectively greater or lower than one. 


\subsection{Regression analysis}

An important strand of research into the performance of universities is based on two-stage analysis, involving evaluation of efficiency (using the DEA methodology) followed by regression analysis to explain the differences in efficiency scores. However, according to Simar and Wilson (2007), log-linear models (estimated using the ordinary least squares (OLS) method), censored regression models (i.e. Tobit models) or other models (estimated using the maximum likelihood (ML) method) are ad hoc rather than structural and are not valid. These authors argued that estimates thus produced are inconsistent because they do not take into account contextual variables as are not based on a well-defined statistical model in which such structures would follow from the first stage in which the initial DEA estimates are obtained.

We based our analysis of institutional and environmental drivers of efficiency on the theoretical work by Simar and Wilson (2011) and an application of it to the higher education system (Wolszczak-Derlacz, Partera 2011). It consists of a truncated regression model which paid special attention to the inference problem that arises from the inherent correlations amongst DEA estimates in finite samples whilst obtaining coherent statistical models that led to meaningful second-stage regressions. Standard errors of coefficients were estimated by the bootstrapping technique $(2,000$ replications).

The dependent variable was inefficiency scores under the VRS assumption and the independent variables included two dummy variables controlling for the effect of having a business incubator or being affiliated to a science park. We predicted that both forms of infrastructure would be associated with better university-industry interactions and hence enhanced innovation and technological spillovers. Because Spain is a country with important regional differences in economic development and territorial investment we also used two exogenous variables to capture the geographic location of universities. Using the Nomenclature of Territorial Units for Statistics (NUTS)-2 division of countries, regional wealth was represented in terms of two proxies, Gross Domestic Product (GDP) per capita and R\&D intensity (R\&D investment over sales). Finally, we controlled for variance in university size (number of students), and age (both of the university and the technology transfer office).

Descriptive statistics for the variables investigated are presented in Table 3. It is worth noting that an increasing proportion of universities acquired business incubators 
and science parks. In 2006 only $43 \%$ of Spanish universities had a business incubator, but by 2010 almost three quarters $(72.7 \%)$ did. Science parks have also become common; in 2010, 9 out of 10 universities had an affiliated science park.

Table 3. Descriptive statistics for the selected variables.

\begin{tabular}{|c|c|c|c|c|c|c|c|c|}
\hline Year & Statistics & $\begin{array}{c}\text { Size } \\
\text { (students) }\end{array}$ & $\begin{array}{l}\text { Age HEI } \\
\text { (years) }\end{array}$ & $\begin{array}{l}\text { Age TTO } \\
\text { (years) }\end{array}$ & $\begin{array}{l}\text { Business } \\
\text { incubator }\end{array}$ & $\begin{array}{l}\text { Science } \\
\text { Park }\end{array}$ & $\begin{array}{c}\mathrm{R} \& \mathrm{D} \\
\text { intensity }\end{array}$ & $\begin{array}{l}\text { Regional wealth } \\
\text { (euros) }\end{array}$ \\
\hline \multirow{4}{*}{2006} & Mean & $24,740.430$ & 139.159 & 14.386 & 0.432 & 0.795 & 0.785 & $22,107.590$ \\
\hline & Std. Dev & $15,957.210$ & 229.174 & 3.895 & 0.501 & 0.408 & 0.315 & $4,390.411$ \\
\hline & Min. & 80,761 & 806 & 20 & 1 & 1 & 1.550 & $28,850.000$ \\
\hline & Max. & 6,501 & 8 & 4 & 0 & 0 & 0.230 & $15,054.000$ \\
\hline \multirow{4}{*}{2008} & Mean & $23,917.430$ & 141.159 & 16.386 & 0.614 & 0.909 & 0.883 & $23,819.750$ \\
\hline & Std. Dev & $15,390.050$ & 229.174 & 3.895 & 0.493 & 0.291 & 0.279 & $4,596.818$ \\
\hline & Min. & 76,537 & 808 & 22 & 1 & 1 & 1.550 & $31,010.000$ \\
\hline & Max. & 5,808 & 10 & 6 & 0 & 0 & 0.250 & $16,341.000$ \\
\hline \multirow{4}{*}{2010} & Mean & $23,878.230$ & 143.159 & 18.386 & 0.727 & 0.932 & 0.903 & $23,031.550$ \\
\hline & Std. Dev & $15,110.270$ & 229.174 & 3.895 & 0.451 & 0.255 & 0.266 & $4,712.055$ \\
\hline & Min. & 73,383 & 810 & 24 & 1 & 1 & 1.330 & $31,314.000$ \\
\hline & Max. & 5,677 & 12 & 8 & 0 & 0 & 0.190 & $16,828.000$ \\
\hline \multirow{4}{*}{ Total } & Mean & $24,178.700$ & 141.159 & 16.386 & 0.591 & 0.879 & 0.857 & $22,986.300$ \\
\hline & Std. Dev & $15,376.330$ & 227.423 & 4.199 & 0.494 & 0.328 & 0.290 & $4,587.449$ \\
\hline & Min. & 80,761 & 810 & 24 & 1 & 1 & 1.550 & $31,314.000$ \\
\hline & Max. & 5,677 & 8 & 4 & 0 & 0 & 0.190 & $15,054.000$ \\
\hline
\end{tabular}

\section{Results}

\subsection{Efficiency and Malmquist}

First we ran a DEA analysis for the three years. A summary of the results is presented in Table 4; they are consistent with earlier analyses of the Spanish higher education system, although they model a different objective function (BerbegalMirabent et al. 2103, Agasisti, Pérez-Esparrells 2010).

Table 4. Descriptive statistics for the efficiency scores.

\begin{tabular}{lccc}
\hline \multicolumn{1}{c}{ Statistic } & 2006 & 2008 & 2010 \\
\hline Mean & 1.1300 & 1.1751 & 1.1937 \\
\hline Median & 1.0027 & 1.0206 & 1.0854 \\
\hline Std. Dev & 0.2015 & 0.2435 & 0.2544 \\
\hline Minimum & 1.0000 & 1.0000 & 1.0000 \\
\hline Maximum & 1.8251 & 1.7714 & 1.8892 \\
\hline \# Efficient units & 22 & 22 & 19
\end{tabular}

Our model suggests that overall universities have become less efficient during the period of interest; inefficiency was $13 \%$ in $2006,17.51 \%$ in 2008 , and $19.37 \%$ in 2010. The number of efficient universities against which the others could be benchmarked also fell, from 22 in 2006 and 2008 to 19 in 2010, signaling that Spanish universities have still not adjusted to the demands imposed by the new regulatory framework. There are several possible interpretations of these results. First, the 
allocation of resources becomes more complicated when faculty members are expected to excel simultaneously at several types of RKT activities. Time is a limited resource and it is difficult to conduct high quality research activities that generate publications, patents, spin-off companies and research projects. Second, universities have yet to find the best way to support research activities whilst also using their resources efficiently. Researchers are often not aware of the potential utility of the TTO and the skills of the staff working there. TTOs' expertise in advising on intellectual property issues, assisting entrepreneurs in the initial stages of business creation and in preparing project proposals should be very valuable in helping academics to transfer their research to the marketplace and deal with the bureaucratic procedures this entails (Caldera, Debande 2010). There is also an urgent need to re-examine how funding is invested. Finally, it is important to note that motivations vary among faculty members; consequently their interest in RKT activities may also vary. Young academics and professors in a weaker contractual position have more incentives to produce research outcomes, which are a way of signaling their academic credentials and thus increasing their chances of obtaining an academic position. These incentives diminish as one's academic career becomes more secure (Lissoni et al. 2011). In the case of full professors the incentives to carry out research may be purely internal, based on personal interest.

Figures in Table 5 show that all Spanish regions are represented. Regional inefficiencies varied from one year to another. It is notable that small regions such as Asturias, Cantabria, Navarra and La Rioja appear to have been fairly efficient throughout the period of interest. Among the regions with multiple universities, Catalunya, Galicia, Castilla y León were the most efficient, on average. 
Table 5. Efficiency in Spanish universities (by region).

\begin{tabular}{llll}
\hline \multicolumn{1}{c}{ Region } & \multicolumn{1}{c}{2006} & 2008 & 2010 \\
\hline Andalucía & $1.1831(3: 8)$ & $1.1720(5: 8)$ & $1.2448(4: 8)$ \\
\hline Aragón & $1.1184(0: 1)$ & $1.0411(0: 1)$ & $1.1149(0: 1)$ \\
\hline Asturias & $1.0414(0: 1)$ & $1.0000(1: 1)$ & $1.0000(1: 1)$ \\
\hline Illes Balears & $1.0978(0: 1)$ & $1.1217(0: 1)$ & $1.4825(0: 1)$ \\
\hline Islas Canarias & $1.4870(0: 1)$ & $1.7173(0: 1)$ & $1.5767(0: 1)$ \\
\hline Cantabria & $1.0000(1: 1)$ & $1.0000(1: 1)$ & $1.0000(1: 1)$ \\
\hline Castilla-La Mancha & $1.0691(0: 1)$ & $1.2821(0: 1)$ & $1.5751(0: 1)$ \\
\hline Castilla y León & $1.0442(2: 3)$ & $1.2032(2: 3)$ & $1.0148(2: 3)$ \\
\hline Catalunya & $1.0169(5: 7)$ & $1.0869(5: 7)$ & $1.0664(5: 7)$ \\
\hline Comunidad Valenciana & $1.2472(2: 5)$ & $1.3303(0: 5)$ & $1.3167(0: 5)$ \\
\hline Extremadura & $1.0000(1: 1)$ & $1.5489(0: 1)$ & $1.3105(0: 1)$ \\
\hline Galicia & $1.1227(1: 3)$ & $1.0722(1: 3)$ & $1.0780(1: 3)$ \\
\hline Madrid & $1.1388(4: 6)$ & $1.2079(3: 6)$ & $1.2092(3: 6)$ \\
\hline Murcia & $1.2809(1: 2)$ & $1.0000(2: 2)$ & $1.3631(1: 2)$ \\
\hline Navarra & $1.0000(1: 1)$ & $1.0000(1: 1)$ & $1.0000(1: 1)$ \\
\hline País Vasco & $1.1930(0: 1)$ & $1.2854(0: 1)$ & $1.2258(0: 1)$ \\
\hline La Rioja & $1.0000(1: 1)$ & $1.0000(1: 1)$ & $1.0000(1: 1)$ \\
\hline $\begin{array}{l}\text { Note: } \text { Each cell contains the average inefficiency of the region. In brackets the first number states for the number of } \\
\text { efficient units within the region, while the second number indicates the number of units located in the region. }\end{array}$
\end{tabular}

Since we have data for three different periods, we wanted to analyze how the performance of universities changed during the period in which we were interested. We therefore calculated the Malmquist index and its decomposition into efficiency and technical change (see Table 6).

Table 6. Malmquist index, efficiency change and technical change (periods 2006-2008, 2008-2010).

\begin{tabular}{lcccccc}
\hline \multirow{2}{*}{ Statistics } & \multicolumn{3}{c}{ 2006-2008 } & & \multicolumn{2}{c}{ 2008-2010 } \\
\cline { 2 - 7 } & Malmquist & $\begin{array}{c}\text { Efficiency } \\
\text { change }\end{array}$ & $\begin{array}{c}\text { Technical } \\
\text { change }\end{array}$ & Malmquist & $\begin{array}{c}\text { Efficiency } \\
\text { change }\end{array}$ & $\begin{array}{c}\text { Technical } \\
\text { change }\end{array}$ \\
\hline Mean & 0.9953 & 0.9693 & 1.0358 & 1.3290 & 0.9710 & 1.3910 \\
\hline Median & 0.9410 & 0.9983 & 1.0454 & 1.2904 & 0.9824 & 1.3742 \\
\hline Std. Dev & 0.2196 & 0.2164 & 0.1226 & 0.2830 & 0.2452 & 0.2067 \\
\hline Min. & 0.6447 & 0.5704 & 0.7215 & 0.7253 & 0.5367 & 0.9990 \\
\hline Max. & 1.8707 & 1.7457 & 1.3478 & 2.2468 & 1.9960 & 1.9641 \\
\hline
\end{tabular}

Over the first two years for which data were analyzed we observed a slight decrease in the Malmquist index. Although the technical change improved, the reduction in the efficiency component determines the overall negative change in performance. Analyses of individual universities revealed that 23 of them had worse results in 2008. However the trend over the next period (2008-2010) was much more encouraging; despite a small decline in efficiency change, overall there was an improvement in the Malmquist index based on a substantial change in technical efficiency. Only 4 out of the 44 universities analyzed had worse technical efficiency in 
2010 than 2008. Moreover, only one of these four universities continued to show a decline in performance over the following two periods.

All in all, the general picture that emerges from this analysis is that there was an improvement in the productivity index during the period we investigated (in 2008-2010 the average Malmquist index was above 1.3). This improvement was not due to efficiency changes (the index was $<1$ in both periods) but to technical advances. This amounts to saying that universities' ability to transform inputs into outputs has actually decreased. One explanation for this result is that universities and academics find it difficult to balance their multiple tasks. Universities are still adapting to the new evaluation framework; it takes time to shift to a research-oriented strategy. Furthermore, time constraints mean that academics have to prioritize and direct their effort towards the activities that are most likely to help them achieve their goals.

There is a different explanation for the improvement in the technical change parameter. Like Agasisti et al. (2011), we define "technology" as the bundle of policies that helps to improve research efficiency. These policies include all the internal programs and initiatives designed to support research activities at universities. Over the years universities have developed specialized infrastructure and services to support such activities. Similarly expenditure on R\&D activities has increased; the efforts university managers make to increase the economic resources devoted to this area of activity reflect the importance they attach to it. All these data seem to indicate that the Spanish higher education system has improved; nevertheless, there remains a need for investigation into the processes by which inputs are transformed into outputs.

\subsection{Regression}

We tested four models of inefficiency scores under the VRS assumption (Table 7). Model 1 merges data from the different years and includes a set of dummy variables to rule out the potential effect of time trends (year 2010 was excluded as the base year). Models 2 to 4 represent specific years.

As far as the control variables are concerned, Model 1 suggests that small universities are better at transforming resources into outcomes; in other words they tend to be more efficient than larger universities. This somewhat contradicts the theory of economies of scale, perhaps suggesting that small universities are easier to manage and therefore can readjust their structures to new demands more easily. Another 
interpretation might be that good results depend not on having a lot of resources but on a competent mass of skilled researchers.

Table 7. Parameter estimates of truncated regression models explaining HEIs inefficiency.

\begin{tabular}{|c|c|c|c|c|}
\hline & $\begin{array}{l}\text { Model } 1 \\
\text { (all) }\end{array}$ & $\begin{array}{l}\text { Model } 2 \\
(2006) \\
\end{array}$ & $\begin{array}{l}\text { Model 3 } \\
(2008) \\
\end{array}$ & $\begin{array}{l}\text { Model } 4 \\
(2010) \\
\end{array}$ \\
\hline Size & $\begin{array}{l}0.3102^{*} \\
(0.1839)\end{array}$ & $\begin{array}{l}-0.0357 \\
(0.2739)\end{array}$ & $\begin{array}{c}0.1890 \\
(0.4234)\end{array}$ & $\begin{array}{c}0.4871 \\
(0.3100)\end{array}$ \\
\hline Age HEI & $\begin{array}{l}-0.1185^{*} \\
(0.0678)\end{array}$ & $\begin{array}{l}-0.0238 \\
(0.0784)\end{array}$ & $\begin{array}{l}-0.0534 \\
(0.1543)\end{array}$ & $\begin{array}{l}-0.1863^{*} \\
(0.1124)\end{array}$ \\
\hline Age TTO & $\begin{array}{c}0.2270 \\
(0.4373)\end{array}$ & $\begin{array}{l}1.4541^{*} \\
(0.8314)\end{array}$ & $\begin{array}{c}0.0889 \\
(0.8888)\end{array}$ & $\begin{array}{l}-0.1505 \\
(0.7162)\end{array}$ \\
\hline Business incubator & $\begin{array}{c}0.0003 \\
(0.1330)\end{array}$ & $\begin{array}{c}0.2643 \\
(0.1997)\end{array}$ & $\begin{array}{c}0.0564 \\
(0.2692)\end{array}$ & $\begin{array}{l}-0.4464^{*} \\
(0.2503)\end{array}$ \\
\hline Science park & $\begin{array}{c}0.2511 \\
(0.3528) \\
\end{array}$ & $\begin{array}{c}0.3436 \\
(0.3527) \\
\end{array}$ & $\begin{array}{c}0.2967 \\
(0.9197) \\
\end{array}$ & $\begin{array}{c}0.6968 \\
(0.7129) \\
\end{array}$ \\
\hline R\&D intensity & $\begin{array}{c}-0.6245^{* *} \\
(0.2893)\end{array}$ & $\begin{array}{c}-0.7470 \\
(0.3306)\end{array}$ & $\begin{array}{l}-0.4356 \\
(0.7966)\end{array}$ & $\begin{array}{l}-0.9997 \\
(0.7234)\end{array}$ \\
\hline Regional wealth & $\begin{array}{c}0.1292 \\
(0.3886)\end{array}$ & $\begin{array}{c}0.3340 \\
(0.5498)\end{array}$ & $\begin{array}{c}0.0811 \\
(0.8012)\end{array}$ & $\begin{array}{c}0.4428 \\
(0.8382)\end{array}$ \\
\hline Year 2006 & $\begin{array}{l}-0.2202 \\
(0.1900)\end{array}$ & & & \\
\hline Year 2008 & $\begin{array}{c}0.0372 \\
(0.1312)\end{array}$ & & & \\
\hline Intercept & $\begin{array}{l}-3.0760 \\
(4.4291)\end{array}$ & $\begin{array}{l}-5.5661 \\
(6.1446) \\
\end{array}$ & $\begin{array}{l}-1.4270 \\
(9.4952)\end{array}$ & $\begin{array}{l}-6.3479 \\
(8.5334) \\
\end{array}$ \\
\hline Sigma & $\begin{array}{c}0.2954^{* * * *} \\
(0.0352)\end{array}$ & $\begin{array}{c}0.1961^{* * * *} \\
(0.0380)\end{array}$ & $\begin{array}{c}0.2889^{* * * *} \\
(0.0623)\end{array}$ & $\begin{array}{c}0.2398^{* * * * *} \\
(0.0418)\end{array}$ \\
\hline Wald $\chi^{2}$ & $19.21^{* * * *}$ & 9.85 & 1.17 & $14.12^{* * *}$ \\
\hline Observations & $\begin{array}{c}132 \\
\text { (69 truncated) }\end{array}$ & $\begin{array}{c}44 \\
(22 \text { truncated) }\end{array}$ & $\begin{array}{c}44 \\
\text { (22 truncated) }\end{array}$ & $\begin{array}{c}44 \\
\text { (25 truncated) }\end{array}$ \\
\hline
\end{tabular}

Note: Robust standard errors adjusted by heteroskedasticity are presented in brackets. *, **, *** indicate significance at the $10 \%, 5 \%$, and $1 \%$, respectively.

The age of a university also seems to shape its efficiency. Although the effect was only significant in Models 1 and 4 the sign of the coefficient was negative in all models. It is possible that older universities have become better at managing resources and hence more efficient in transforming inputs into outputs. The negative association between TTO age and efficiency provides evidence against this hypothesis. Model 2 revealed that young TTOs were more efficient. We used the Mann-Whitney U-test to examine this finding in more detail; we failed to detect any differences between universities using this test and so the negative association observed in Model 2 should be treated with caution.

Another key finding is that science parks and business incubators had relatively little impact on efficiency; our analyses suggested that although they are supposed to boost RKT activities, they do not help improve universities' efficiency. The exception was Model 4, where the business incubator variable had a modest effect. In the full model this effect was diluted. Incubators and science parks emerged in the 90s and 
spread throughout the Spanish university system in response to various policies designed to promote knowledge transfer activities. Universities developed these infrastructures very rapidly; however, it seems that they have failed to develop strategies to use them efficiently.

As for the regional variables, the regional GDP per capita did not have a significant effect on efficiency; however the regional R\&D intensity reveals a positive influence on efficiency in 2006. The profound economic downturn that Spain suffered in 2008 and the consequent dramatic reduction in investment might explain why this variable did not have a significant effect on efficiency in 2008 or 2010. Nevertheless, the positive association was also present in the full model, indicating that regions which have more $R \& D$ activity provide a more favorable environment for RKT activities, which in turn makes their universities more efficient. We can therefore conclude that region does influence Spanish universities' efficiency.

All in all, the results of this analysis support the hypothesis that whilst some structural factors do influence universities' efficiency, for the most part universities rely heavily on internal resources and capabilities to achieve their objectives.

\section{Discussion and conclusions}

In the recent years the Spanish higher education system has undergone important modifications and RKT outcomes have increasingly been viewed as critical determinants of an academic institution's success. The movement from a teachingoriented model towards a research-oriented one has led to significant changes in the way universities allocate internal resources and capacity.

Using data from three different periods (before, during and after the reforms) we analyzed how the efficiency of Spanish public universities has changed over time. We found that the number of efficient units and the mean average efficiency score diminished during the period investigated. We observed that although productivity declined in terms of "pure" efficiency, there were substantial improvements in terms of technical change. We then categorized universities into seven groups according to the changes they experienced over the period of interest. The final stage of our analysis, a truncated regression, suggested that certain external factors -the size and age of the university, the age of the TTO, the existence of specific infrastructures (business incubators), and the R\&D intensity of the region-influence universities' efficiency. 
This study has several policy implications. First, although universities are expected to excel at both basic (i.e. publications) and applied (i.e. patents, spin-offs, research projects) research activities, it is clear that the current Spanish incentive system does not support this. There should be reconsideration of the weights assigned to the various activities in evaluation procedures and ranking systems (both at university and researcher level). Moreover, there are calls from both public and private organizations across the world for a narrowing of the gap between academy and industry, and an emphasis on research outputs with clear practical uses. Some countries have begun to promote closer links between knowledge institutions, trade and industry, with areas like Silicon Valley (California) and Route 128 (Boston) at the forefront of these developments; however in Europe, and Spain in particular, there is a long way to go. Recently, in June 2015 a new reform was introduced (Royal Decree 415/2015), modifying the evaluation criteria and standards for civil-servants. The new standards are expected to allow a more balanced assessment of the merits of the applicant, particularly, in terms of technology transfer activities. In the next few years, when data will be available, it will be worth analyzing its impact on RKT outcomes.

Second, academics are asked to teach and perform managerial tasks as well as carrying out RKT activities. This forces them to prioritize the activities that will produce them the greatest benefit - which is usually stability security. This has two important policy implications. The first has to do with the typical academic career trajectory. We suggest that there is scope to introduce different career paths corresponding to the differentiation between teaching and research oriented academic profiles. Spain could follow the example of countries such as the UK or USA where such models have been successful. The second issue concerns the workload of contemporary academics. Some of the administrative tasks currently performed by academics could be performed effectively by administrative staff, but budget restrictions have made it difficult for universities to expand their workforces. This leads us to question whether the current structure of the higher education system is appropriate.

Third, although the vast majority of Spanish universities have developed specialist infrastructure and services to support RKT activities (i.e. technology transfer offices, science parks, business incubators), there is still room for improvement. As the efficiency analysis revealed, there need to be improvements to current internal 
structures and resource management systems. Perhaps more horizontal and transparent processes improve the efficiency with which inputs are transformed into outputs.

Although we believe this study provides useful insights into the efficiency of universities we identified some limitations. It should be noted that although DEA is a robust technique, the sensitivity of the results is closely tied to the model specification (the variables selected and the orientation chosen). In addition, like any other analytical technique DEA models cannot capture the potential effects of non-controllable factors on the performance of the production units under analysis. The other limitations relate to the specificity of the context: we analyzed institution in the Spanish public higher education system and the period of analysis - chosen in order to examine the impact of reforms to the system- coincided with a major economic downturn, which might complicate the interpretation of the results.

\section{References}

Abramo, G.; D'Angelo, C. A.; Pugini, F. 2008. The measurement of Italian universities' research productivity by a non parametric-bibliometric methodology, Scientometrics 76(2): 225-244. http://dx.doi.org/10.1007/s11192-007-1942-2.

Agarwal, R.; Ohyama, A. 2013. Industry or academia, basic or applied? Career choices and earnings trajectories of scientists, Management Science 59(4): 950-970. http://dx.doi.org/10.1287/mnsc.1120.1582.

Agasisti, T.; Dal Bianco, A.; Landoni, P.; Sala, A.; Salerno, S. 2011. Evaluating the efficiency of research in academic departments: An empirical analysis in an Italian Region, Higher Education Quarterly 65(3): 267-289. http://dx.doi.org/ 10.1111/j.1468-2273.2011.00489.x.

Agasisti, T.; Pérez-Esparrells, C. 2010. Comparing efficiency in a cross-country perspective: The case of Italian and Spanish state universities, Higher Education 59(1): 85-103. http://dx.doi.org/10.1007/s10734-009-9235-8.

Agasisti, T.; Pohl, C. 2012. Comparing German and Italian public universities: Convergence or divergence in the higher education landscape?, Managerial and Decision Economics 33(2): 71-85. http://dx.doi.org/10.1002/mde.1561.

Anderson, T. R.; Daim, T. U.; Lavoie, F. F. 2007. Measuring the efficiency of university technology transfer, Technovation 27(5): 306-318. http://dx.doi.org/10.1016/j.technovation.2006.10.003.

Balsmeier, B.; Pellens, M. 2014. Who makes, who breaks: Which scientists stay in academe?, $\quad$ Economics $\quad$ Letters $122(2): \quad 229-232$. http://dx.doi.org/10.1016/j.econlet.2013.11.033.

Berbegal-Mirabent, J.; Lafuente, E.; Solé, F. 2013. The pursuit of knowledge transfer activities: An efficiency analysis of Spanish universities, Journal of Business Research 66(10): 2051-2059. http://dx.doi.org/10.1016/j.jbusres.2013.02.031. 
Berbegal-Mirabent, J.; Sánchez García, J. L.; Riberio-Soriano, D. E. 2015. Universityindustry partnerships for the provision of R\&D services, Journal of Business Research 68(7): 1407-1413. http://dx.doi.org/10.1016/j.jbusres.2015.01.023.

Berbegal-Mirabent, J.; Solé, F. 2012. What are we measuring when evaluating universities' efficiency?, Regional and Sectoral Economic Studies 12(3): 31-46.

Boardman, P. C.; Bozeman, B. 2007. Role strain in university research centers, Journal of Higher Education 78(4): 430-463. http://dx.doi.org/10.1353/jhe.2007.0020.

Boardman, P. C.; Ponomariov, B. L. 2007. Reward systems and NSF university research centers: The impact of tenure on university scientists' valuation of applied and commercially relevant research, Journal of Higher Education 78(1): 51-70. http://dx.doi.org/10.1353/jhe.2007.0000.

Caldera, A.; Debande, O. 2010. Performance of Spanish universities in technology transfer: An empirical analysis, Research Policy 39(9): 1160-1173. http://dx.doi.org/10.1016/j.respol.2010.05.016.

Chambers, R. G.; Pope, R. D. 1996. Aggregate productivity measures, American Journal of Agricultural Economics 78: 1360-1365.

Charnes A.; Cooper, W. W.; Rhodes, E. 1978. Measuring the efficiency of decision making units, European Journal of Operational Research 2(6): 429-444. http://dx.doi.org/10.1016/0377-2217(78)90138-8.

Coccia, M. 2008. Measuring scientific performance of public research units for strategic change, Journal of Infometrics 2(3): 183-194.

Coelli, T.; Prasada Rao, D. S.; Battese, G. E. 1998. An introduction to efficiency and productivity analysis. Boston: Kluwer.

Cooper, W.; Seiford, L.M.; Tone, K. 2007. Data Envelopment Analysis: A comprehensive text with models, applications, references and DEA-Solver software. 2nd ed. Breiningsville, USA: Springer.

Färe, R.; Grosskopf, S.; Lindgren, B.; Roos, P. 1992. Productivity changes in Swedish pharmacies 1980-1989: A non-parametric Malmquist approach, Journal of Productivity Analysis 3(1/2): 85-101. http://dx.doi.org/10.1007/978-94-017-1923$\underline{0 \_6}$.

Färe, R.; Grosskopf, S.; Norris, M.; Zhang, Z. 1994. Productivity growth, technical progress, and efficiency change in industrialized countries, American Economic Review 84(1): 66-83.

Farrell, M. J. 1957. The measurement of productive efficiency, Journal of Royal Statistical Society (A, general) 120(3): 253-281.

Geuna, A.; Muscio, A. 2009. The governance of university knowledge transfer: A critical review of the literature, Minerva 47: 93-114. http://dx.doi.org/10.1007/s11024-009-9118-2.

Groot, T.; García-Valderrama, T. 2006. Research quality and efficiency. An analysis of assessments and management issues in Dutch economics and business research programs, $\quad$ Research $\quad$ Policy $\quad 35(9)$ : $1362-1376$. http://dx.doi.org/10.1016/j.respol.2006.07.002.

Hazelkorn, E. 2005. University research management: Developing research in new institutions. Paris: OECD. 
Hsu, D. W.; Shen, Y. C.; Yuan, B. J.; Chou, C. J. 2015. Toward successful commercialization of university technology: Performance drivers of university technology transfer in Taiwan, Technological Forecasting and Social Change 92: 25-39. http://dx.doi.org/10.1016/j.techfore.2014.11.002.

Kao, C.; Hung, H. T. 2008. Efficiency analysis of university departments: An empirical study, Omega 36(4): 653-664. http://dx.doi.org/10.1016/j.omega.2006.02.003.

Kim, Y. 2013. The ivory tower approach to entrepreneurial linkage: Productivity changes in university technology transfer, Journal of Technology Transfer 38: 180197. http://dx.doi.org/10.1007/s10961-011-9217-8.

Koopmans, T. C. 1951. An analysis of production as an efficient combination of activities. In T. C. Koopmans (Ed.). Activity analysis of production and allocation. Cowles Commission for Research in Economics, Monograph, 13, New York: Wiley.

Lissoni, F.; Mairesse, J.; Montobbio, F.; Pezzoni, M. 2011. Scientific productivity and academic promotion: a study on French and Italian physicists, Industrial and Corporate Change 20(1): 253-294. http://dx.doi.org/10.1093/icc/dtq073.

Plewa, C.; Korff, N.; Johnson, C.; Macpherson, G.; Baaken, T.; Rampersad, G. C. 2013. The evolution of university-industry linkages. A framework, Journal of Engineering and Technology Management 30: 21-44. http://dx.doi.org/10.1016/j.jengtecman.2012.11.005.

Rasmussen, E. 2008. Spin-off venture creation in a university context. An entrepreneurial process view. Bodø: Bodø Graduate School of Business.

Ray, S. C. 2004. Data Envelopment Analysis: Theory and Techniques for Economics and Operations Research. New York: Cambridge University Press.

Salerno, C. 2004. What we know about the efficiency of higher education institutions: The best evidence. University of Twente (The Netherlands): The Center for Higher Education Policy Studies.

Sarrico, C. S.; Rosa, M. J.; Teixeira, P. N.; Cardoso, M. F. 2010. Assessing quality and evaluating performance in higher education: Worlds apart or complementary views?, Minerva 48(1): 35-54. http://dx.doi.org/10.1007/s11024-010-9142-2.

Seiford, L. M.; Thrall, R. N. 1990. Recent developments in DEA: The mathematical programming approach to frontier analysis, Journal of Econometrics 46: 7-38. http://dx.doi.org/10.1016/0304-4076(90)90045-U.

Shattock, M. 2009. Entrepreneurialism in universities and the knowledge economy. London, UK: Society for Research into Higher Education and Open University Press.

Soares, L. 2012. The rise of big data in higher education [online], [cited 18 August 2015]. Available from Internet: http://www.educause.edu/library/resources/rise-bigdata-higher-education.

Simar, L.; Wilson, P. W. 2011. Two-stage DEA: Caveat emptor, Journal of Productivity Analysis 36(2): 205-218. http://dx.doi.org/10.1007/s11123-011-0230-6.

Simar, L.; Wilson, P. W. 2007. Estimation and inference in two-stage, semi-parametric models of production processes, Journal of Econometrics 136: 31-64. http://dx.doi.org/10.1016/j.jeconom.2005.07.009. 
Tone, K.; Sahoo, B. 2003. Scale, indivisibilities and production function in data envelopment analysis, International Journal of Production Economics 84(2), 165192. http://dx.doi.org/10.1016/S0925-5273(02)00412-7.

van der Ploeg, F.; Veugelers, R. 2008. Towards evidence-based reform of European universities, CESifo Economic Studies 5(2): 99-120. http://dx.doi.org/10.1093/cesifo/ifn015.

van Raan, A. F. J. 2005. Fatal attraction: Conceptual and methodological problems in the ranking of universities by bibliometric methods, Scientometrics 62(1): 133-143. http://dx.doi.org/10.1007/s11192-005-0008-6.

Wolszczak-Derlacz, J.; Partera, A. 2011. Efficiency of European public higher education institutions: a two-stage multi-country approach, Scientometrics 89(3): 887-917. http://dx.doi.org/10.1007/s11192-011-0484-9. 